\title{
The evolution of hydrogen research: Is Germany heading for an early lock-in?
}

\author{
Marko P. Hekkert ${ }^{\mathrm{a}, *}$, Jan-Frens van Giessel ${ }^{\mathrm{b}}$, Menno Ros $^{\mathrm{a}}$, Martin Wietschel ${ }^{\mathrm{c}}$, \\ Marius T.H. Meeus ${ }^{\mathrm{a}}$ \\ ${ }^{a}$ Department of Innovation Studies, Copernicus Institute for Sustainable Development and Innovation, Utrecht University, The Netherlands \\ ${ }^{\mathrm{b}}$ Technopolis BV, Herengracht 141, 1015 BH Amsterdam, The Netherlands \\ ${ }^{\mathrm{c}}$ Department of Energy Policy and Energy Technology, Fraunhofer Institute for Systems and Innovation Research ISI, Breslauer Strasse 48, \\ 76139 Karlsruhe, Germany
}

Available online 17 May 2005

\begin{abstract}
In this article we analyse and evaluate the German Research and Development (R\&D) system related to the development of hydrogen technology for mobile applications. We analysed both research projects and patents in the period 1974-2002. The paper focuses on an analysis of the main technological trends, the role of governments in steering the transition and an evaluation of the speed and direction of the transition to hydrogen. Our findings show that the attention for hydrogen is strongly increasing and that overall the variety in research projects is increasing. This is positive. However, some technologies receive more attention than others. The number of projects and patents related to infrastructure and refuelling is very low while on board production of hydrogen is a clear winner. In terms of storage, liquid hydrogen receives most attention. We are concerned about these directions in R\&D strategy since different well to wheel studies have shown the drawbacks of these options in terms of energy efficiency. Different governments play an active role in stimulating research and development, which broadens the variety of research topics, which is positive. However, the distance between government and industrial interests may be too large to lead to a significant influence of policy efforts. We therefore recommend stronger policy coordination to counteract the risks of premature lock-in in suboptimal hydrogen technologies.

(c) 2005 International Association for Hydrogen Energy. Published by Elsevier Ltd. All rights reserved.
\end{abstract}

\section{Introduction}

Hydrogen is considered by many a promising future energy carrier. The advantages of using hydrogen are the avoidance of harmful emissions when converted into useful energy (electricity or heat) and the potential to produce hydrogen based on renewable resources. Another advantage is the promise of a very efficient conversion technology, the fuel cell, that runs very well on hydrogen and less on other fuels. Since, the dependence on fossil fuels, the issue of

\footnotetext{
* Corresponding author. Tel.: +310302536112; fax: +31302533939 .

E-mail address: m.hekkert@geog.uu.nl (M.P. Hekkert).
}

climate change and the local air pollution in large cities are high on political agendas, the high expectations of hydrogen as fuel can be well understood.

Hydrogen as fuel also has disadvantages. Hydrogen has a low energy density. Therefore, compression or liquification is necessary, which requires a significant amount of energy and makes the fuel more difficult to handle. Furthermore, changing the current system into a system that supports hydrogen as energy carrier is a massive operation concerning massive costs. Finally, the fuel cell is not fully developed which results in suboptimal performance and high costs.

So, even though hydrogen is considered a promising energy carrier, the road towards large scale use of hydrogen is uncertain. To increase the chance that a transition to 
hydrogen will take place sufficient knowledge on the production, transport, storage and conversion of hydrogen is necessary. This knowledge production takes place in a socalled hydrogen innovation system.

An hydrogen innovation system consists of all the actors, institutions and their relations that influence the development, diffusion and ulilization of hydrogen as an energy carrier (after [1]). To increase the chance that hydrogen will become the dominant energy carrier of the future, it is necessary that the hydrogen innovation system performs well. The aim of this paper is to evaluate the German hydrogen innovation system.

In the EU, Germany is a frontrunner in the amount of hydrogen research and development projects [2]. In Germany, many R\&D projects are aimed at the transport sector. Most major car manufactures in Germany, especially DaimlerChrysler and BMW, invest large amounts of money in the R\&D of hydrogen and fuel cell technologies. Besides spending of these organizations, the German federal government stimulated the development of hydrogen and fuel cell technologies since 1980 by funding research projects $\left(\mathrm{BMBF}^{1}\right.$ and $\mathrm{BMWi}{ }^{2}$ funding). The focus of these funded projects in the period 1980-1995 was mainly on electrolysis, demonstration and fleet test of automotives with hydrogen propulsion, and the use of hydrogen in fuel cells [3]. Since 1996 until 2000 hydrogen and fuel cell research is part of the Fourth Energy Research and Technology Program and has a budget of $€ 10$ million per year [4]. The BMBF funded projects in this period focuses on the development of system components that will serve to improve the potential for hydrogen production, storage and conversion. Cost reductions of key components like fuel cell technologies and electrolysis are considered important.

In the evaluation of the German hydrogen innovation system a number of criteria are considered to be important. First, for innovation systems that are in an early stage of development variety in the knowledge base is of crucial importance since it may reduce the chance of heading for a suboptimal lock-in. Various studies show that when technologies are competing, the sequence of adopters determines the final outcome of the competition, i.e., there is path dependence in technology selection. When returns are increasing with the number of adopters of a particular technology, a small degree of dominance of a technology in the early stages becomes self-reinforcing. Therefore, early adoption decisions for one or another technology have a major effect on future adopters that will follow previous decisions and cause lock in of an industry within one technology [5]. When this technology is suboptimal, a problem exists. Examples of suboptimal technologies that were locked in are the Qwerty layout of keyboards, the VHS standard in video equipment and light water nuclear reactors [5]. An undesired premature lock in of a poor performing hydrogen system is less likely

\footnotetext{
${ }^{1}$ BMBF: Federal Ministry of Research and Technology.

${ }^{2}$ BMWi: Federal Ministry of Economy and Technology.
}

to occur when all actors in the hydrogen innovation system remain flexible in their choice of technology. This requires variety in the knowledge base.

Second, for a succesful transition towards hydrogen it is important that a minimal amount of knowledge regarding all major subsystems of the hydrogen system (production, transport, storage, conversion) is to be present in a country or region (see Table 1 for an overview of these subsystems and the potential technological diversity per subsystem). This is not only important for the obvious reason that building an hydrogen system requires knowledge of all building parts of such a system but is also important in terms of 'advocacy coalitions'. With the latter, we mean that a process of change requires a community of people that believe in the new system and lobby for a process of change. When this advocacy coalition has roots in all subsystems of the new system, chances increase that a change really will take place.

Third, it is important that public and private initiatives are in line. It works both ways: when public policy initiatives dominate and the market lags behind a process of change is not likely to take place. When market initiatives are frustrated by slow or opposite public initiatives a process of change is also likely to slow down.

Therefore, in this paper we evaluate the German hydrogen innovation system based on three criteria: variety of the knowledge base, missing aspects in the knowledge base and the interaction between public and private initiatives. Since Germany has strong automotive sector we focus on hydrogen as fuel for the transport sector.

In the next section, we will explain which methodology we used and then we will discuss the German hydrogen innovation system per subsystem of the hydrogen system. We will end with discussion and conclusion.

\section{Methodology}

To evaluate the German hydrogen innovation system we constructed a database with $\mathrm{R} \& \mathrm{D}$ projects and patents per subsystem of the hydrogen system. The data of the R\&D projects is collected from different databases. The Cordis database [6], the Fökat database [7], and the German hydrogen database [3] have been used. The projects are selected using two main criteria. Firstly, only projects that focus on hydrogen or fuel cell technologies for the transportation sector are taken into account. Projects that focus on, for instance, methanol production and storage are not taken into account. Secondly, only projects are selected where at least one German actor is a participant of the project. In total 229 projects are collected for the time period 1974-2003. To complete the information on the content and organization of the R\&D projects found in the databases, additional information was collected by contacting the project coordinator or R\&D manager. Furthermore, an overview of all the demonstration projects on hydrogen powered vehicles, busses, and refuelling stations [8] and the Deutsche 
Table 1

Overview of system, subsystem and technological options

\begin{tabular}{|c|c|c|c|c|c|}
\hline \multirow{2}{*}{$\begin{array}{l}\text { System } \\
\text { Subsystem }\end{array}$} & \multicolumn{5}{|c|}{ Hydrogen-based transportation sector } \\
\hline & Production & Distribution & Refuelling & Storage & Conversion \\
\hline Technological options & $\begin{array}{l}\text { Steam reforming } \\
\text { Partial oxidation } \\
\text { Electrolysis }\end{array}$ & $\begin{array}{l}\text { Pipeline } \\
\text { Truck } \\
\text { Ship }\end{array}$ & $\begin{array}{l}\text { Gaseous } \\
\text { Liquid }\end{array}$ & $\begin{array}{l}\text { Gaseous } \\
\text { Liquid } \\
\text { Metal hydride } \\
\text { Carbon nanotubes } \\
\text { Graphitic nanofibres } \\
\text { Zeolites }\end{array}$ & $\begin{array}{l}\text { Hydrogen Internal combustion engine (ICE) } \\
\text { PEM Fuel cell (FC) }\end{array}$ \\
\hline
\end{tabular}

Table 2

Sources of the R\&D projects and patents collected

\begin{tabular}{lcc}
\hline \multirow{2}{*}{ Source } & \multicolumn{2}{c}{ Number of } \\
\cline { 2 - 3 } & projects & patents \\
\hline EU-Cordis & 52 & \\
Deutsche Wasserstoff Verband (DWV) & 11 & \\
German hydrogen database - Hyweb & 111 & \\
BMBF - Fökat & 43 & \\
Other & 12 & 241 \\
European Patent Office (EPO) & & \\
& & 241 \\
Total & 229 & 241 \\
\hline
\end{tabular}

Wasserstoff Verband [9] are used. The data on R\&D projects are dominated by (partly) public funded $R \& D$ projects since the disclosure of publicly funded projects is much larger than private $R \& D$ projects. To ensure that also the private R\&D initiatives are taken sufficiently into account for all German actors involved in R\&D projects a patent search is conducted. Patents can be seen as one of the outcomes of R\&D projects. The patents are collected from the database of the European Patent Office [10]. European and national patents are evaluated. In total, 241 patents are added to our database for the time period 1974-2003. Table 2 provides an overview of the sources from which the projects and patents are collected. ${ }^{3}$

\footnotetext{
${ }^{3}$ Patents are an indicator for R\&D activity since it is used by firms to benefit commercially from its technology. This indicator, however, is far from perfect since firms also have other ways of appropriating the effects of its investments, for example, secrecy. Sometimes the product characteristics do not make it necessary to patent since e.g. product complexity is so high that imitation is very difficult or many complementary assets are necessary to make an invention successful. Therefore, only a part of all $R \& D$ is covered by patent research.
}

\subsection{Technology focus}

The technology focus per subsystem is analyzed by calculating the cumulative amount of R\&D projects and patents for each technological option per year. The slope of the curve indicates the acceleration of the R\&D activity and is used to indicate if the technology focus shifts over time. For both patent and project data, we constructed cumulative annual distributions rather than the conventional annual distributions. We use cumulative distributions to underscore the effects of increasing returns in R\&D activity. Lockin phenomena result from increasing returns to adoption, which are modelled as dependent on all previous adoption decisions [5].

\subsection{Technological variety}

The technological variety is determined by using the concept of 'entropy'. The entropy of a distribution of R\&D projects or patents among technologies is given by (1) $[5,11]$ :

$H=-\sum_{i=1}^{m} p_{i} \ln p_{i}$,

where $H$ indicates the technological variety present in the distribution of R\&D projects and patents among technologies. $p_{i}$ indicates the share of $\mathrm{R} \& \mathrm{D}$ projects or patents of one technological option $i(i=1 \ldots m)$ in all the R\&D projects or patents. The distribution is characterized by minimum entropy when one single technology completely dominates the amount of R\&D projects or patents. In this case, $H=0$. A distribution is characterized by maximum entropy when all technologies have an equal share in the total amount of R\&D projects or patents. In this case $H=1 / \mathrm{m}$.

\section{Results}

Section 3.1 shows a descriptive overview of the amount of $\mathrm{R} \& \mathrm{D}$ projects and the patents present in the hydrogen system. The next section gives a descriptive overview of the 


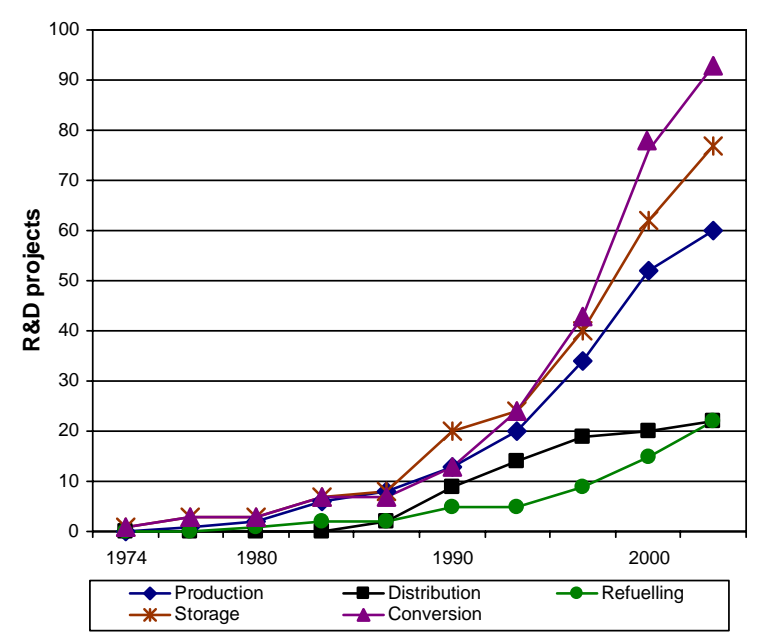

Fig. 1. Cumulative amount of R\&D projects in time for the different subsystems.

amount of R\&D projects and patents present in subsystems production (Section 3.2), storage (Section 3.5), and conversion (Section 3.6). The subsystems distribution and refuelling are left out of the technology analysis, because there is not enough data to show any interesting results.

\subsection{Complete hydrogen system}

Fig. 1 presents the cumulative amount of $R \& D$ projects per subsystem. This figure shows that the most R\&D projects focus on the conversion of hydrogen, followed by storage and production of hydrogen. The R\&D activities in the subsystems distribution and refuelling seem to be of less importance, given the small amount of projects in these subsystems. The slopes of the production, storage, conversion curves show an increasing acceleration of the $R \& D$ projects from 1990 until period 2003. The R\&D activities in the subsystems distribution and refuelling show less acceleration.

Fig. 2 presents the cumulative amount of patents for the five different subsystems. This figure shows that most patents are applied in the subsystem production followed by the conversion subsystem. For the subsystems distribution and refuelling, no patents are found. The subsystem storage shows the highest amount of patents until 1995 but then the strong growth of patents in the subsystem production and conversion overtake the storage initiatives.

When Figs. 1 and 2 are compared, several observations can be made. Firstly, there is a time lag of 6 years (for production) and 9 years (for conversion) between the acceleration of the amount of R\&D projects and the amount of patents in the subsystems production and conversion. Secondly, Fig. 1 shows that, after conversion, the most R\&D projects are conducted in the subsystem storage. On the other hand, Fig. 2 shows that the amount of patents in the subsystem storage is very low compared with the amount

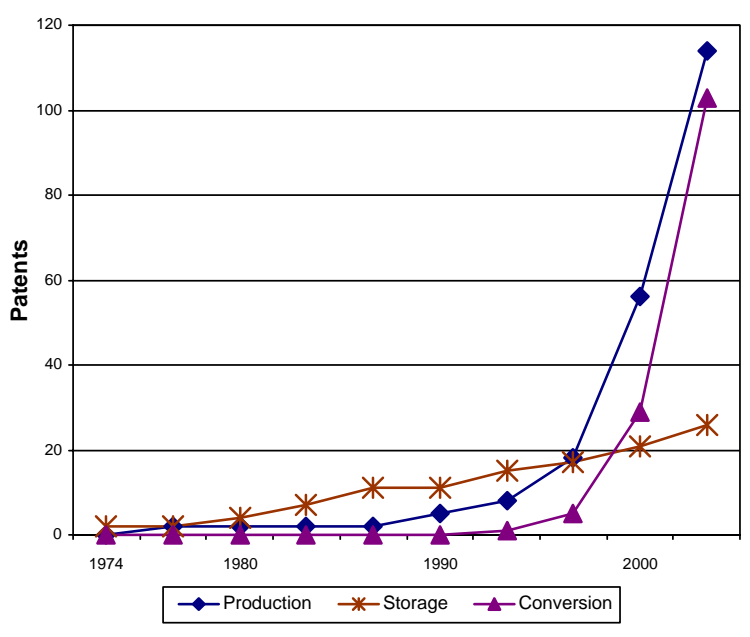

Fig. 2. Cumulative amount of patents in the different subsystems.

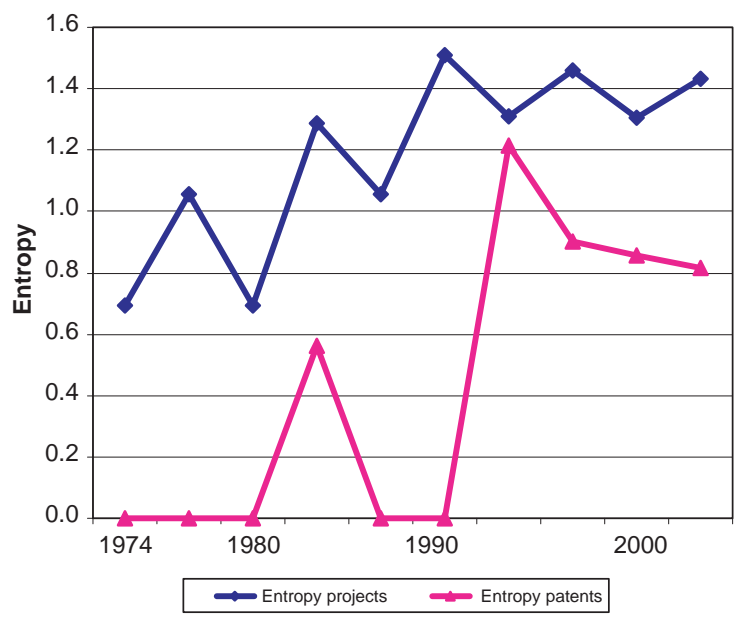

Fig. 3. Entropy for the hydrogen transport system.

of patents for the subsystems production and conversion. A possible explanation is that the storage problem is regarded as very important in public R\&D programs but less important in private $R \& D$ programs.

Fig. 3 shows the entropy for the R\&D projects and patents in the hydrogen transport system. The entropy is based on the distribution of $R \& D$ projects or patents among the five subsystems. A scale form 0.0 to 1.6 is used, because the maximum entropy value for five technology fields is $\ln 5=1.6$. The entropy of the projects shows a fluctuating pattern of increasing and decreasing entropy between 1974 and 2003. However, the trend of the projects entropy is increasing until 1989 and then stabilizes around 1.4. This is close to the maximum value, which indicates a great variety of the $R \& D$ projects among the five subsystems. A lock-in of R\&D activity into one subsystem is not likely to occur. The entropy 


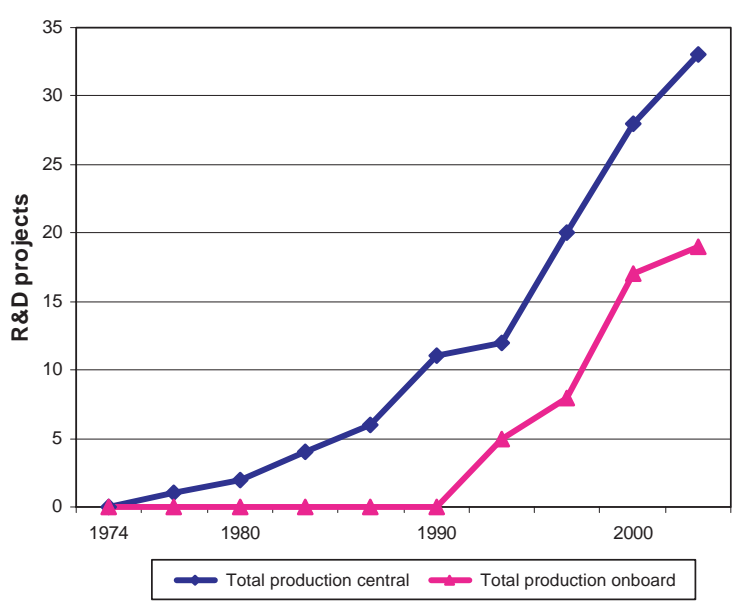

Fig. 4. Cumulative amount of projects for the subsystem production for the categories onboard and central production of hydrogen.

value for the patents shows a different pattern. There is a peak in 1983 and 1992, but from 1992 the patents entropy decreases. Comparing this with the results of Fig. 2, the decrease in patents entropy is caused by a patent focus on the subsystems production and conversion.

These results suggest that in the (partly) public funded R\&D programs the creation of variety in the knowledge base is high on the agenda while the private $R \& D$ programs seem to focus on hydrogen production and conversion.

\subsection{Subsystem production}

In the subsystem production four technological options are present, namely electrolysis of water, partial oxidation, steam reforming, and purification of hydrogen. These technologies can be either categorized as onboard production or central production of hydrogen. Steam reforming and partial oxidation are technologies can be used both onboard the vehicle and for central production of hydrogen. Electrolysis of water is classified as a central production technology either at large scale or on-site at the refuelling station. Based on the project or patent description, the technologies are characterized as onboard or central production technology.

Fig. 4 clearly indicates that most projects focus on technological options for the central production of hydrogen, but technologies for the onboard production of hydrogen grow in importance from 1989 onwards. The acceleration rate between 1989 and 1994, and between 1995 and 2000 is higher for onboard technologies than for central production technologies. This indicates that onboard production of hydrogen is growing in importance compared to the central production of hydrogen in these years. However, central production is still considered most important in terms of the number of $R \& D$ projects.

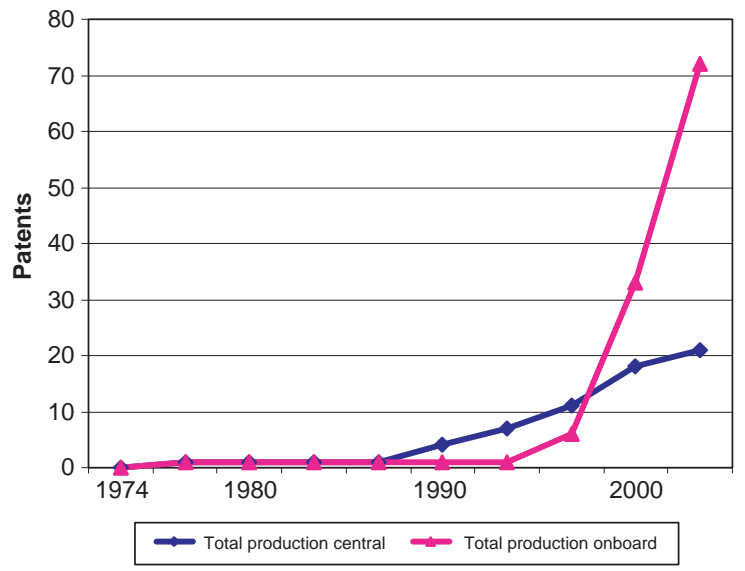

Fig. 5. Cumulative amount of patents for the subsystem production for the categories onboard and central production of hydrogen.

Fig. 5 shows the amount of patents for the categories onboard and central production of hydrogen. The pattern differs strongly from the R\&D projects. In this case the number of patents explode for on board production in recent years. This dwarfs the patent number for central hydrogen production. Apparently, the infrastructural problems of hydrogen distribution are taken seriously in the German industry, which results in an R\&D shift towards on board production.

When Figs. 4 and 5 are compared, several observations can be made. Firstly, it is shown that most R\&D projects focus on central production (especially electrolysis), while most patents are applied for onboard production of hydrogen (especially on steam reforming). Secondly, a time lag of 6 years between the R\&D projects and patents focusing on onboard production is noted.

Again, a difference in technology focus is observed between the amount of R\&D projects (central production technologies) and the amount of patent (onboard technologies).

\subsection{Subsystem storage}

In the subsystem storage four technological options are present, namely storage of gaseous and liquid hydrogen, storage in metal hydrides, and other storage techniques like carbon nanotubes, graphite nanofibres, and zeolites.

Fig. 6 shows the cumulative amount of $R \& D$ projects for the technological options in the subsystem storage. Most R\&D projects focus on the gaseous and liquid storage of hydrogen. The amount of R\&D projects for these two options accelerates strongly from 1992. From 1992 until 2003 a slower acceleration of R\&D projects focussing on other technologies to store hydrogen, like carbon nanotubes, nanofibres and zeolites, took place. Between 1974 and 1994, many R\&D projects focussed on the storage of hydrogen in metal hydrides, but from 1992 the number of 


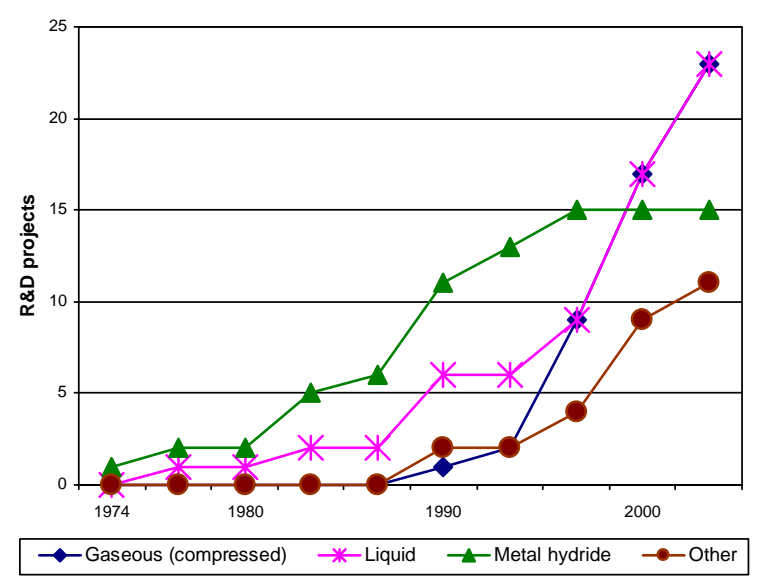

Fig. 6. Cumulative amount of projects for the subsystem storage.

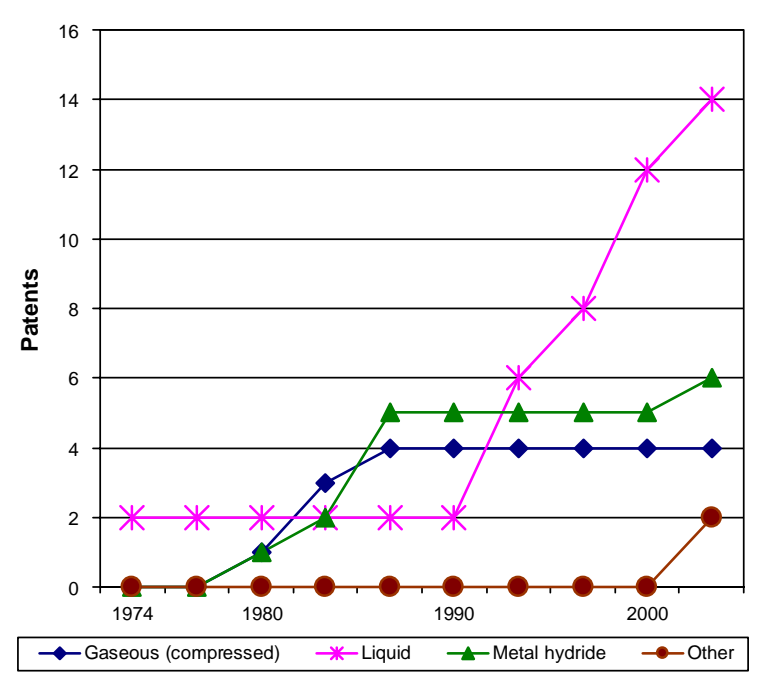

Fig. 7. Cumulative amount of patents for the subsystem storage.

$\mathrm{R} \& \mathrm{D}$ projects focussing on metal hydrides is decreasing and shows no new activity in the following years.

The cumulative amount of patents for the technological options in the subsystem storage is shown in Fig. 7. The figure shows that the number of patents related to hydrogen storage is relatively small. Also, in the period before 1990, both gaseous and metal hydride storage received most attention in the patents. After 1990 liquid storage of hydrogen is clearly the most intensively patented option.

When Figs. 6 and 7 are compared it clearly shows that the $R \& D$ projects dedicated hydrogen storage in liquid or gaseous form and in metal hydrides as mainly led to patents in liquid storage. This may have a number of explanations. First, the research projects focusing on the other two storage techniques were not as successful, or the $R \& D$ projects were

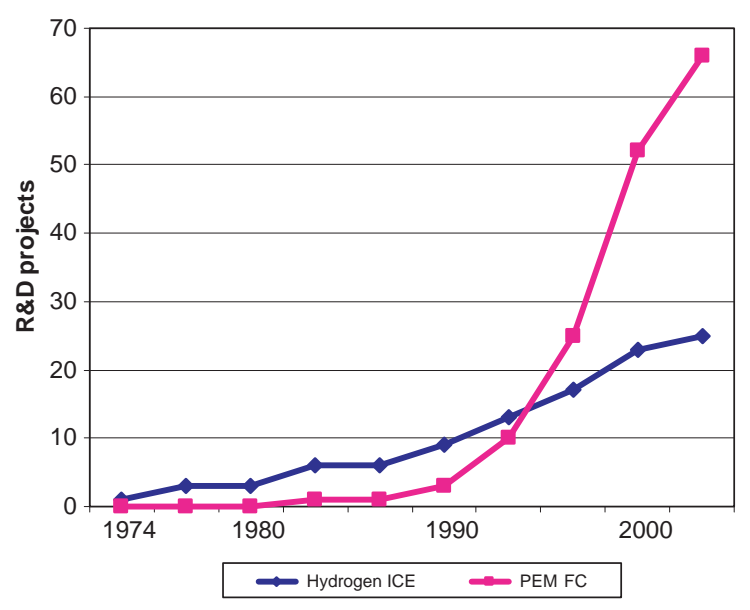

Fig. 8. Cumulative amount of projects for the subsystem conversion.

focusing more strongly on the development and testing than on new fundamental insights.

\subsection{Subsystem conversion}

For the subsystem conversion two technological options are considered in the field, namely the hydrogen combustion engine and the PEM fuel cell. Only the figure for the $\mathrm{R} \& \mathrm{D}$ projects is presented, since no patents were found for the hydrogen ICE. All patents were related to fuel cell technology.

Fig. 8 shows the cumulative amount of R\&D projects for the technological options in the subsystem conversion. Most R\&D projects focus on the technological option PEM fuel cell. Between 1974 and 1991 the hydrogen ICE has the highest amount of R\&D projects and greatest acceleration in $R \& D$ projects. In 1991 this changes when the slope of the PEM fuel cell curve accelerates more strongly than the slope of the hydrogen combustion engine. This trend still continues.

\section{Discussion of results}

Based on the trends in projects and patents for the German hydrogen R\&D system, it is now possible to answer the following questions: What are the major technological trends in the German R\&D system? What is the role of public-funded projects? And, is the transition towards a hydrogen economy developing in the right direction? By answering these questions we will also reflect on the key-questions stated in the introductions regarding variety of the knowledge base, missing aspects in the knowledge base and the interaction between public and private initiatives. 


\subsection{What are the major technological trends in the German hydrogen $R \& D$ system?}

The first trend that is clearly visible is that the attention for hydrogen has been growing explosively in the last decades. Overall, a sharp rise of R\&D projects and patents is visible. However, not all technological options have received equal attention. In terms of patents, on board production of hydrogen is a clear winner and so is the fuel cell as conversion technology. This combination of technologies needs to be seriously taken into account as a possible winning combination. The lack of projects and patents that are devoted to distributing and fuelling of hydrogen supports this.

When hydrogen will be produced off board, our analysis shows two options that have the best assets. The project analysis shows a sharp rise of gaseous and liquid hydrogen storage in recent years at the expense of physical-chemical absorption technologies. The patents clearly show an increasing interest in the storage of liquid hydrogen. This is a logical trend since liquid hydrogen has the highest energy density. However, when the future hydrogen system will be based on liquid hydrogen the well to wheel efficiency of the hydrogen chain will be quite low due to the high-energy requirements of liquefaction [12].

\subsection{What is the role of public-funded projects?}

A higher variety in technological options is visible for the projects than for the patents. This means that due to public funded projects specific options are researched more intense than that would be the case without the public funding. Since we already indicated that variety in the knowledge base is important in this stage of technological development, the effects of public funded projects on the system can be regarded as positive.

However, the results also show that the attention distribution over the technological options strongly differs for the projects and patents. This means that companies that are involved in (partly) publicly funded research focus on a wide range of subjects but that their patent activity is limited to a smaller range of options that are of specific interest to them. A clear division is visible between the public focus on off-board production of hydrogen while the private focus is more related to on-board production of hydrogen. Furthermore, public research is more strongly focused on electrolysis as production method while the market interest is more strongly focused on chemical conversion of fuels into hydrogen.

Therefore, based on the results we conclude that policy effort succeeds in increasing the variety of the knowledge base but that the difference in interest between government and industry may be too large to steer the R\&D activities in a desired direction.

\subsection{Is the transition towards a hydrogen economy developing in the right direction?}

Evaluation of the hydrogen related $R \& D$ projects and patents leaves us with mixed feelings regarding the speed and direction in which the R\&D system is progressing. On one hand, it is positive that hydrogen as a research topic has clearly taken of in Germany. On the other hand we have concerns about the direction in which the $R \& D$ system is developing. This is based on two visible preferences in the system: on board production and liquid hydrogen. From well to wheel studies we have learned that on board production of hydrogen leads to inefficient systems [12,13]. The same holds for using liquid hydrogen [12].

Since the whole idea of using hydrogen as transportation fuel is the reduction of environmental impacts of mobility, we have concerns about the seemingly preferences of the German R\&D system which seems to prefer inefficient routes.

These seemingly preferences are not difficult to explain. The car manufacturing industry dominates the commercial interest in hydrogen technology in Germany. Their competences are related to developing and building cars and not to the development of a hydrogen infrastructure. The fact that a hydrogen infrastructure is essential to sell hydrogen-fuelled cars creates a large uncertainty for car manufacturers since they are dependent on third parties to ensure their economic viability.

Two possible strategies can be followed by car manufacturers, which are currently both visible. The first is to reduce these uncertainties by focusing on their own competences and developing cars that fit on the existing infrastructure. This strategy is clearly supported by our patent analysis. A second strategy is being active in social network building to mobilize sufficient commitment to create a collective effort in infrastructure development. Examples of these activities are the Californian Fuel Cell partnership, the hydrogen experiments in Iceland and the German Transport Energy Strategy [14].

The second strategy does not eliminate the uncertainties regarding dependency on other actors. This can be underpinned by the following example. Oil companies are involved in the Californian Fuel Cell partnership and are involved in testing hydrogen-refuelling stations. This suggests an interest in a hydrogen infrastructure. On the other hand, one of these oil companies initiates collaborative R\&D projects with the car manufacturing industry to test technology, which is focused on on-board production of hydrogen (Shell - Daimler projects). This ambiguity is fully understandable, since they have large sunk costs in the current fuel infrastructure and the costs for upgrading this infrastructure towards a hydrogen infrastructure are likely to be on their shoulders, but creates inherent uncertainties for car manufacturers.

What is the logical way out of this visible trend in the German $R \& D$ sector? As argued earlier, the $R \& D$ behaviour of 
the car manufacturing industry can be explained by the uncertainties they perceive in terms of infrastructure development and these uncertainties are very difficult to manage. A way out therefore, depends strongly on reducing the uncertainties regarding infrastructure. This requires a strong party that acts as a system intermediary. The role of this intermediary is to bring together the parties involved in a future hydrogen economy (like is done in the Californian Fuel Cell Partnership) but is also capable of arranging strong commitments in terms of infrastructure development. Hereby reducing the uncertainty for all actors involved. Since the stakes are so high and the process so capital intensive this is a role that most likely only a strong government can play. This is in line with history that shows that the majority of our current infrastructures (roads, electricity, natural gas) are controlled and coordinated by governments. When the transition to hydrogen is really taken seriously by governments, just funding of R\&D is likely not to be sufficient. A strong coordination effort should accompany these financial initiatives.

\section{Conclusions}

Our evaluation of the R\&D part of the German hydrogen innovation system shows that the attention for hydrogen during the last 30 years is strongly increasing and that the variety of hydrogen related $R \& D$ projects has increased during the last 30 years. These are both positive trends when one considers a hydrogen economy desirable.

However, our evaluation also shows a clear threat. The variety of patents is decreasing during the last 10 years. The patent intensity of German firms involved in hydrogen research indicates a preference for on board reforming of hydrogen in contrast to central production. In case of central production, liquid hydrogen receives significantly more attention than other forms of hydrogen storage. Since both technologies are suboptimal in terms of sustainability an early lock-in of these technologies not desirable. It might very well lead to a suboptimal hydrogen system that may be difficult to alter.

Finally, our analysis showed that public influence on the hydrogen $R \& D$ system increased the variety in terms of research project, which is positive. A clear threat, however, is that the distance between visions of a desirable hydrogen energy system of public and private actors, respectively, seems to be too large for successful steering of R\&D focus by German or European government. A stronger coordination effort by governments therefore seems necessary.

\section{References}

[1] Jacobsson S, Johnson A. The diffusion of renewable energy technology: an analytical framework and key issues for research. Energy Policy 2000;28(9):625-40.

[2] Bahbout A, Tartaglia GT, Buenger U. Hydrogen activities in the European Union Work-programme. In: 21e world gas conference, 2000, Nice, France.

[3] LB-Systemtechnik, Hydrogen data, website, 20 November 2002.

[4] Dooley JJ, Runci PJ. Energy Research and Development in Germany. 1999, Pacific Northwest National Laboratory, Washington, DC.

[5] Frenken K, Hekkert MP, Godfroij P. Technological variety and organizational competition in the transition towards sustainable car technology. Technol Forecasting Soc Change 2004;71:485-507.

[6] European Comission, cordis database, website http://dbs. cordis.lu/search/en/simple/EN_PROJ_simple.html, 20 October 2002 .

[7] BMBF, German Federal Ministry of Research and Technology, Fökat database, website http://oas2.ip.kp.dlr.de/ foekat/foekat/foekat, 12 January, 2003.

[8] LB-Systemtechnik, Hydrogen data, website http://www. h2data.de, 20 November 2002.

[9] DWV, Deutscher Wasserstoff- und Brennstoffzellen-Verband, overview of hydrogen activities, website http://www. dwv-info.de, 20 October 2002.

[10] European-Patent-Office, Overview of Hydrogen related patents, website http://ep.espacenet.com/, 17 January, 2003.

[11] Frenken K, Saviotti PP, Trommetter M. Variety and niche creation in aircraft, helicopters, motorcycles and microcomputers. Res Policy 1999;28:469-88.

[12] Hekkert MP, Faaij APC, Hendriks F, Neelis ML. Natural gas as an alternative to crude oil in automotive fuel chains wellto-wheel analysis and transition strategy development. Energy Policy 2005;33:579-94.

[13] Ogden JM. Prospects of building a hydrogen energy infrastructure. Ann Rev of Energy Environ 1999;24:227-79.

[14] TES, Transport Energy Strategy: A joint initiative from politics and industry, Federal Ministry of Transport, Building and Housing, Germany. 